ÉGYPTE

monde arabe

\section{Égypte/Monde arabe}

29 | 1997

Mélanges

\title{
Entre tradition soufie et réformisme musulman : la littérature hagiographique dans le soufisme égyptien contemporain
}

\section{Rachida Chih}

\section{CpenEdition}

Journals

Édition électronique

URL : https://journals.openedition.org/ema/256

DOI : 10.4000/ema.256

ISSN : 2090-7273

Éditeur

CEDEJ - Centre d'études et de documentation économiques juridiques et sociales

Édition imprimée

Date de publication : 31 mars 1997

Pagination : 23-36

ISSN : 1110-5097

Référence électronique

Rachida Chih, «Entre tradition soufie et réformisme musulman : la littérature hagiographique dans le soufisme égyptien contemporain », Égypte/Monde arabe [En ligne], 29 | 1997, mis en ligne le 08 juillet 2008, consulté le 07 juillet 2022. URL : http://journals.openedition.org/ema/256 ; DOI : https://doi.org/ 10.4000/ema.256

Ce document a été généré automatiquement le 7 juillet 2022

Tous droits réservés 


\title{
Entre tradition soufie et réformisme musulman : la littérature hagiographique dans le soufisme égyptien contemporain
}

\author{
Rachida Chih
}

1 Les recueils biographiques ou hagiographiques constituent par excellence la littérature du soufisme. Le vocable le plus précis, pour traduire la notion française d'hagiographie, est manâqib (pluriel de manqaba : « discours des vertus»). Les manâqib sont tout à la fois un discours sur les prodiges et miracles des saints et un récit sur la vie, la personnalité spirituelle et les vertus des docteurs de l'islam. Les tabaqât, biographies de personnages religieux groupées par "classes» d'âge, s'apparentent au style des manâqib. Ainsi, les célèbres tabaqât du soufi égyptien 'Abd al-Wahhâb al-Sha'rânî (m. 1566) foisonnent de

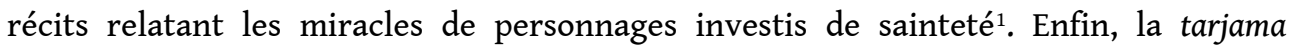
désigne aussi bien la biographie que l'hagiographie ; c'est le contenu même du texte qui lui donne un statut différent.

2 Les récits du comportement exemplaire, des faits et gestes extraordinaires des savants et des saints constituent une littérature très prisée à l'époque médiévale. Une partie de cette littérature est consacrée aux fondateurs de confréries soufies (tarîqa, terme qui désigne aussi bien l'organisation que l'enseignement soufis). Celles-ci se développent dès le $\mathrm{xII}^{\mathrm{e}}$ siècle et codifient en règles (âdâb, usûl) l'enseignement et la tradition mystique dont elles sont les héritières. Parallèlement, la vénération des disciples à l'égard du shaykh fondateur de la tarîga ou de son héritier spirituel (khalîfa) facilile l'essor du culte des saints. Les principales confréries égyptiennes se réclament des grands saints de l'époque médiévale, les quatre pôles suprêmes (qutb, pl. aqtâb) dans la hiérarchie des saints intercesseurs : les deux Irakiens 'Abd al-Qâdir al-Jilânî (m. 1166) et Ahmad al-Rifầî (m. 1175), le Maghrébin Ahmad al-Badawî (m. 1276) et l'Égyptien Ibrâhîm al-Disûqî (m. 1288). À cette liste il faudrait ajouter un autre grand saint originaire du Maghreb, Abû-l-Hasan al-Shâdhilî (m. 1258). Les confréries dont ils sont 
les fondateurs éponymes se sont en général constituées longtemps après leur disparition; mais les récits merveilleux de leurs prodiges et de leurs charismes n'ont cessé, de leur mort à nos jours, d'alimenter leur légende et de garder leur mémoire vivante.

Dès la fin du XVIII ${ }^{\mathrm{e}}$ siècle, des mouvements de réforme veulent revenir à une application stricte du message coranique et purifier l'islam des superstitions et légendes introduites par les confréries, en premier lieu le culte des saints. Au Xx siècle, les confréries et le soufisme connaissent un certain déclin ; la littérature hagiographique laisse la place aux ouvrages de fiqh qui inondent le marché actuel du livre religieux en Égypte. Seules quelques vies de grands saints de l'époque médiévale continuent de se vendre à bon marché aux dévots lors des mawlid (pl. mawâlid: mouleds, fêles de l'anniversaire des saints).

4 Or, si la littérature hagiographique n'attire plus le grand public, cela ne signifie pas que le genre est éteint ; il survit, se reproduit et se transmet à l'intérieur des cercles fermés de soufis. En effet, les enquêtes menées au sein d'un réseau confrérique khalwatî en Haute-Égypte m'ont permis de collecter un certain nombre de bio-hagiographies consacrées à des soufis contemporains, dont certains sont morts il y a à peine une trentaine d'années. La persistance d'une tradition hagiographique écrite et orale témoigne d'un phénomène plus ample, à savoir la persistance de pratiques et de croyances liées au soufisme et au culte des saints et profondément ancrées dans tous les niveaux de la société égyptienne. Si les confréries soufies ont perdu leur place dans la vie politique et intellectuelle égyptienne, elles sont loin d'y représenter un mouvement marginal. Les pèlerinages et festivités qu'elles organisent autour des tombeaux de saints ou des membres de la famille du Prophète (ahl al-bayt) sont l'occasion de vastes rassemblements. Mais comment les confréries et le soufisme continuent-ils d'exister et de se perpétuer aujourd'hui en Égypte? L'étude des itinéraires religieux et spirituels de trois maîtres de la Khalwatiyya, reconstitués à partir de leurs biographies et des témoignages de leurs disciples, offre un accès au monde et à la culture des soufis. Leur évolution dans l'Égypte contemporaine, sera mise en parallèle avec celle de l'islam réformiste, légaliste et rigoriste, devenu l'islam officiel du pays.

La Khalwatiyya en Égypte : une confrérie de lettrés

5 Les soufis dont j'ai étudié la carrière religieuse et l'itinéraire spirituel ont contribué à la diffusion de la confrérie Khalwatiyya en Haute-Égypte dans la deuxième moitié du XIX siècle et tout au long $\mathrm{du} \mathrm{xx}^{\mathrm{e}}$. D'origine turco-persane, la Khalwatiyya est une des confréries les plus répandues en Égypte, son centre principal aujourd'hui dans le monde musulman. Elle ne saurait représenter toutes les confréries du pays et encore moins tout le soufisme, mais elle en possède de nombreux traits.

D'abord assimilée, de par ses origines, aux milieux turc et persan du Caire du $\mathrm{xVI}^{\mathrm{e}}$ au xvIII ${ }^{\mathrm{e}}$ siècles, elle devient - et demeure - la confrérie de l'élite azharie à partir du milieu du XVIIIe siècle ${ }^{2}$. La diffusion de la Khalwatiyya au sein d'al-Azhar (la plus haute autorité sunnite, N.D.L.R.) est liée à l'affiliation du shaykh de cette mosquée, Muhammad b. Salîm al-Hifnî (m. 1767), à la confrérie par un maître d'origine syrienne, Mustafa al-Bakrî (m. 1749). Grâce à al-Hifnî, la confrérie va s'étendre sur tout le territoire égyptien par l'intermédiaire d'azharis d'origine rurale. De retour dans leur milieu natal, ils répandent la tarîga dans les mosquées. L'attrait qu'exerce la Khalwatiyya sur al-Azhar s'explique par l'accent qui est mis dans cette confrérie sur 
l'union entre sharî'a et haqîqa, sur l'application de la loi divine, la conformité au modèle prophétique et la connaissance intérieure de Dieu obtenue par illumination (fath). Cet idéal religieux représente celui de nombreux ulémas de l'époque. L'expansion de la Khalwatiyya en Haute-Égypte est liée à deux facteurs historiques: le rôle des éliles locales d'origine tribale et l'influence d'al-Azhar.

7 C'est un neveu du shaykh Hummâm (m. 1769), chef de la tribu des Hawwâra, qui demande au shaykh al-Hifnî de lui envoyer un de ses disciples pour enseigner la religion et répandre la tarîqa ${ }^{3}$. Au XVIIIe siècle, les Hawwâra régnent sur un Haut Sa'îd unifié, assurent une paix relative dans la région et encouragent la vie religieuse et culturelle. Des villes de Haute-Égypte telles Jirjâ et Banî 'Adî fournissent de nombreux étudiants à al-Azhar, dont le prestige est immense à cette époque. Un des proches disciples du shaykh al-Hifnî est un azhari originaire de Banî 'Adî, Ahmad al-Dardîr (m. 1786\} : il est responsable de la loge (riwâq) des étudiants de Haute-Égypte à al-Azhar ainsi que l'administrateur de leurs biens de mainmorte (waqf) et leur mufti. Il initie un grand nombre d'étudiants $s a^{\prime} \hat{i} d \imath^{4}$ qui, de retour au village, étendent la tarîqa. La majorité des branches actuelles de la Khalwatiyya en Haute-Égypte se réclament du shaykh al-Dardîr. Les trois soufis au sujet desquels j'ai travaillé, Ahmad Sharqâwî (m. 1899), 'Abd al-Jawâd al-Dûmî (m. 1943) et Ahmad al-Tayyib (m. 1955), sont le produit de ces circonstances particulières qui ont conduit à l'implantation de la Khalwatiyya en Haute-Égypte. Ils ont tous trois suivi des études religieuses avant d'être initiés au soufisme et de devenir des guides spirituels.

Itinéraires de trois maîtres de la Khalwatiyya

9 J'ai reconstitué la carrière religieuse et l'itinéraire spirituel de ces soufis en m'appuyant sur les biographies qui leur ont été consacrées ainsi que sur les informations obtenues par enquêtes orales auprès des disciples et fidèles ; très peu, parmi eux, les ont connus de leur vivant, mais tous croient en leur sainteté et recherchent leur baraka, qui continue selon eux d'irradier après leur mort.

10 Hagiographie écrite et hagiographie orale, bien que s'intéressant toujours à la sainteté des shaykh, mettent en avant différents aspects de la manière dont s'est fait l'accès à cette sainteté. Les variations tiennent à l'origine sociale des biographes et des disciples. Les biographies de maîtres spirituels sont écrites, comme c'est courant au sein des confréries, par leurs proches disciples. Dans la Khalwatiyya, le cercle restreint des proches du shaykh est généralement composé de lettrés qui ont étudié à al-Azhar, alors que la masse des fidèles appartient à des milieux très populaires.

Profil des hagiographes

11 Hasanayn Muhammad Makhlûf, ancien mufti d'Égypte et membre du corps des grands ulémas d'al-Azhar, a consacré un courte biographie à Ahmad Sharqâwî et à son fils Abûl-Wafâ' (m. 1961), Safahât nasî'a, publiée en 1961. Le père de l'auteur, M. Hasanayn Makhlûf, fut un proche disciple du shaykh Sharqâwî ainsi qu'un important 'âlim du tournant du siècle; il encouragea la réforme d'al-Azhar à travers les multiples fonctions qu'il occupait à l'université. Muhammad 'Abduh al-Hajjâjî́ ${ }^{5}$ est l'ancien responsable des manuscrits arabes et persans de la bibliothèque de l'université du Caire. Il s'est notamment intéressé à l'histoire religieuse du Sa'îd, à laquelle il a consacré plusieurs ouvrages ${ }^{6}$. Il est l'auteur d'un recueil biographique sur des personnalités religieuses du Sa'îd au xx siècle, Min a'Iâm al-Sa'îd fîl-qarn al-râbi' 'ashar al-hijrî, essentiellement consacré à Ahmad Sharqâwî et à ses proches disciples et publié en 1969. Les ouvrages manuscrits de l'historien natif de Jirjâ, Muhammad al-Marâghî 
al-Jirjâwî (m. 1924), contiennent des informations succintes et dispersées sur le shaykh Sharqâwî, notamment son histoire locale sur la ville de Jirjâ, Ta'tîr al-Nawâhî wa-l-arjâ' fì man ishtahara min 'ulamâ' $w a$ ayân madînat al-Sa'îd. Jirjâ, copié en $1922^{7}$, et son dictionnaire biographique sur les revivificateurs de l'islam, Wasîlat al-mujadîn fì sharh hadîfh al-mujadîn wa tarâjim al-mujaddidîn ${ }^{8}$, M. al-Marâghî est un lettré du Sa'îd qui a étudié à al-Azhar; ses écrits font une grande place aux soufis, étant lui-même un proche disciple du shaykh Sharqâwî.

(ân shaykh 'Abd al-Jawâd al-Dûmî, intitulée al-'Arif al-Dûmî, fut écrite par deux disciples formés à al-Azhar, 'Abd al-Rahmân al-Tâhir et 'Abd al-Rahîm Mahmûd'. Les deux auteurs n'ont pas connu le shaykh al-Dûmî de son vivant, mais ont recueilli des informations auprès de la première génération de disciples, qui l'ont longuement fréquenté. La rédaction de l'ouvrage fut menée sous la direction d'un proche disciple du shaykh al-Dûmî, Muhammad al-Tâhir, khalîfa de la Khalwatiyya dûmiyya ramliyya de 1954 à 1977. H. Khalîl, ancien enseignant dans les écoles publiques, relate de manière vivante les souvenirs qu'il a conservés du shaykh al-Dûmî alors qu'il était jeune étudiant à al-Azhar, dans un court ouvrage intitulé al-Wafâ', publié en 1986. L'ouvrage biographique du shaykh Ahmad al-Tayyib et de son fils Muhammad (m. 1988) est encore à l'état de manuscrit. Selon le shaykh actuel, Muhammad M. al-Tayyib, azhari et enseignant dans un lycée hôtelier, et son frère, Ahmad al-Tayyib, azhari également, docteur en philosophie et doyen de de la faculté des fondements de la religion (kulliyat usûl al-dîn) à Assouan, cette biographie met en avant de façon excessive les miracles de leurs ancêtres.

Formation religieuse et initiation mystique des shaykh

Ahmad Sharqâwî est un célèbre soufi du XIXe siècle dont les écrits, édités, se trouvent à la Bibliothèque nationale du Caire (Dâr al-Kutub) ainsi qu'à celle de l'université d'alAzhar. Il étudie les sciences religieuses dans les mosquées-madrasa de Jirjâ avant d'être initié à la Khalwatiyya par un maître de Tahta. Le shaykh Sharqâwî ne donne pas son nom à une confrérie organisée, mais son autorité spirituelle n'en rayonne pas moins dans toute la région de Jirjâ. Notable important, il compte parmi ses disciples aussi bien des chefs de tribus et des membres de l'aristocratie terrienne que des ulémas d'alAzhar.

Le shaykh 'Abd al-Jawâd al-Dûmî est un sa'îdî originaire de Tahta qui, grâce à ses études à al-Azhar, devient imam dans différentes mosquées du Caire ${ }^{10}$. Il est initié à la Khalwatiyya par un maître de la région d'Asyût. La mosquée al-Sabtiya, dans le quartier de Bûlâq, où il exerce pendant près de vingt ans, devient le centre de son enseignement spirituel, d'où sa tarîqa va s'étendre. Il s'entoure de disciples, dont des étudiants azharis originaires du Sa'îd qui formeront le noyau de sa confrérie. De son vivant, le shaykh ne désigne pas de successeur : il s'ensuit à sa mort un conflit de succession entre ses deux disciples les plus proches. La confrérie se scinde en deux branches distinctes, la Khalwatiyya Dûmiyya et la Khalwatiyya Ramliyya.

L'exemple du shaykh Ahmad al-Tayyib al-Hassânî représente un troisième cas de figure. Après des études à al-Azhar où il est initié à la Khalwatiyya par le shaykh Abû Bakr alHaddâd ${ }^{11}$, il fonde dans le village d'al-Qurna, situé sur la rive orienlale du Nil en face de Louxor (province de Qéna), une tarîqa, la Khalwatiyya Hassâniyya, en même temps qu'une dynastie soufie : c'est son petit-fils qui, à la suite de son fils, dirige aujourd'hui la confrérie. 

aujourd'hui riches et prospères ; ils sont aussi devenus de saints personnages, c'est-àdire des hommes considérés comme si proches de Dieu que leurs prières sont exaucées. Ainsi peuvent-ils intercéder entre les croyants et le divin. Comment ces hommes ont-ils réussi à se faire reconnaître au sein de leur communauté comme des guides religieux et spirituels ? Comment devient-on « saint », en Égypte, au xxe siècle?

Le savant soufi dans le champ de la spiritualité, ils représentent un type propre qui les distingue d'autres mystiques, ce qu'E. Geoffroy appelle un archétype spirituel, "sortes de matrices sur lesquelles se fondent leur conduite $»^{12}$. Les shaykh ont le même comportement spirituel et donc social; la connaissance de la sharî́a et des sciences islamiques, liée à celle de la voie mystique et l'engagement dans la réforme de la société, sont pour ces maîtres, du moins dans le discours de leurs hagiographes, le seul accès à la sainteté. Les shaykh représentent le profil du 'âlim 'âmil, du savant qui met sa foi en pratique. Ainsi une large place est-elle réservée dans leur biographie aux étapes de l'apprentissage religieux, et les formules ne manquent pas pour qualifier le degré de connaissances acquises dans tous les domaines.

Les trois hommes apprennent le Coran par cœur en un temps record, avant leur dixième année. Jeunes et brillants étudiants, ils suivent un long apprentissage religieux avant d'être initiés au soufisme. Selon les biographes du shaykh al-Dûmî, ce dernier assimile très vile les textes les plus difficiles, doué en cela d'une rare faculté de mémorisation ${ }^{13}$. Dans la longue liste de ses maîtres à al-Azhar figurent, entre autres, le shaykh al-islâm Salîm al-Bishri (m. 1917) et le président de la Jam'iyya al-nahda al-dîniyya al-islâmiyya, Yûsuf al-Dijwî (m. 1946). Le shaykh al-Dûmî montre un certain penchant pour les hadîth (traditions prophétiques) et le tafsîr (exégèse coranique); il étudie les deux gloses du Sahîh (recueil de traditions prophétiques) d'al-Bukhârî (m. 870), le Muwaththâ' (traité de jurisprudence) de l'imam Mâlik et le tafsîr de Baydâwî (m. 1286). Ses commentaires du Coran, publiés dans la revue al-Islâm, seront regroupés après sa mort par ses disciples dans un ouvrage intitulé Mîn nafahât al-Dûmî. À al-Azhar, Ahmad al-Tayyib suit les cours donnés à la faculté des fondements de la religion: 'aqîda (dogme), falsafa (philosophie) et tasawwuf (mystique). Quant à Ahmad Sharqâwî, il est l'auteur d'une épître, Shams al-tahqî $q^{14}$ qui reçut, selon les témoignages de ses biographes, les éloges des plus grands ulémas d'al-Azhar de son temps, dont le shaykh Muhammad 'Ilaysh (m. 1882) qui occupa les charges de shaykh du rite malékite et de mufti d'Égypte, et le shaykh Hasûna al-Nawâwî (m. 1924), shaykh d'al-Azhar puis mufti d'Égypte ${ }^{15}$.

19 La fréquentation d'une institution comme al-Azhar, qui possédait encore, au début du siècle, un prestige aujourd'hui perdu en Égypte et des maîtres célèbres, garantit pour ces hommes la solidité de la formation et l'authenticité du savoir. À la connaissance des sciences extérieures, ils allient la connaissance mystique, objet elle aussi d'une longue initiation auprès d'un maître qualifié jusqu'à l'obtention de l'ijiza (certificat de transmission). L'appartenance à une silsila de maîtres connus est essentielle : elle valide la prétention au rôle de guide spirituel. « Nombreux, écrit al-Najânisî, sont ceux qui ont accusé le shaykh Sharqâwî de ne pas avoir de silsila. Or certains shaykh - ils sont rares -, ont directement été initiés par le Prophète et n'appartiennent donc pas à une tarîga ; 
mais pour pouvoir initier à leur tour des disciples, ils doivent recevoir l'idhn (autorisation) d'un shaykh reconnu. C'est ce qui s'est passé pour notre maître. $~^{16}$

Les biographes nous présentent des hommes qui allient ce qu'il faut savoir à ce qu'il faut être: des shaykh entièrement engagés dans leur rôle d'enseignant et de guide, animés par un souci de réformer leur société dans une période présentée comme celle d'une dégénérescence de l'islam en général et de la voie mystique en particulier. Les noms de nos trois personnages sont précédés d'un certain nombre de qualificatifs qui les rangent dans une catégorie spirituelle définie. Le qualificatif le plus souvent attaché au nom du shaykh Sharqâwî est celui de " revivificateur de la religion » (mujaddid al-dîn) et de rénovateur de la voie mystique et de ses préceptes ${ }^{17}$. Le shaykh propage le Coran et la Sunna, écrivent ses biographes, à une époque où la communauté des musulmans vit dans l'ignorance et l'obscurantisme. Cette ignorance est entretenue à des fins lucratives par ce qu'ils appellent les ahl al-turuq, les confréries populaires à dominante rurale - qui n'auraient pas à leur têle de shaykh qualifié ${ }^{18}$. C'est la qualité de guide, au sens de dâ'î, celui qui appelle les musulmans à revenir dans le droit chemin (al-tarîq almustaqîm), qui paraît déterminante dans son action. Il est considéré comme un soufi réformateur.

21 'Abd al-Jawâd fait toute sa carrière dans le quartier populaire de Bûlâq, au Caire. Il est présenté comme un 'âlim dont la vie est centrée sur ses fonctions d'imam et de guide spirituel. Il transforme de simples lieux de prière (zâwiya) en mosquées où peuvent se rassembler un grand nombre de fidèles pour son prône du vendredi. Ses qualités d'enseignant et de commentateur du Coran et des hadîth sont louées : «Tous les jeudis, après la prière du coucher du soleil, le shaykh commentait des hadîth tirés de l'ouvrage Dalîl al-fâlahîn fî sharh riyâd al-sâlihîn d'al-Nawâwî. Il commentait le Coran après la prière commune du vendredi $»^{19}$. Lettrés et ulémas venaient assister à ses leçons, et nombreux sont les gens de Bûlâq qu'il a éloignés de la corruption (fasâd) et de l'égarement (dalâl) et remis sur le droit chemin ${ }^{20}$.

L'auteur de la biographie du shaykh Ahmad al-Tayyib, encore à l'état de manuscrit, ignore à quelle date précise ce dernier s'installe dans le village d'al-Qurna ; peut-être après ses études à aI-Azhar, au tournant du siècle? Il est présenté comme un infatigable propagateur de l'islam; toujours à cheval, il allait de village en village pour enseigner la religion à une époque où la population, entièrement composée de paysans, baignait dans la superstition, les croyances magiques et l'ignorance. Il aurait sorti les croyants de l'obscurantisme et revivifié leur piété.

La recherche de la légitimité religieuse

23 Les récits relatifs à la vie des shaykh de la Khalwatiyya s'inscrivent davantage dans le style de la tarjama, la biographie, que dans celui de l'hagiographie. Ils présentent les personnages engagés dans la réforme de leur société, ne faisant que peu de place aux récits miraculeux. En écrivant sur leur shaykh, les biographes .écrivent sur leur propre milieu, donc sur eux-mêmes et sur l'idée qu'ils se font de la voie mystique et du rôle du guide spirituel. Ces hommes ont été formés à al-Azhar, ainsi leur idéal soufi est-il de mener à Dieu à travers l'enseignement du Coran et du modèle prophétique. C'est leur propre portrait qui se reflète dans ces biographies, celui de garants et défenseurs du véritable soufisme, en lutte contre les pratiques et croyances introduites par les confréries populaires et qui ont à leurs yeux contribué à jeter le discrédit, sur le soufisme. Les soufis lettrés mettent peu en avant leur affiliation confrérique, insistant surtout sur leurs liens avec le milieu des ulémas en général, alors que les membres de 
confréries plus populaires comme la Ahmadiyya ou la Burhâmiyya affichent leur appartenance confrérique en défilant avec leur bannière et leurs couleurs.

Les karâmât (miracles) ne sont pas mis en avant, mais ils ne sont pas entièrement occultés; ils sont là pour apporter la preuve de la sainteté du shaykh. Ce dernier cependant ne doit pas s'abaisser à ce premier degré de la voie mystique, car son statut ne repose pas sur sa capacité à faire des miracles - contrairement au saint thaumaturge dont il se distingue - mais sur ses qualités d'enseignant et de guide. Quant ils sont mentionnés, les karâmât s'articulent autour de la lutte contre les responsables de bid'a (innovations blâmables), le plus grand karâmâ des shaykh étant le nombre de musulmans qu'ils ont remis sur le droit chemin et de disciples dont ils se sont entourés. Pour les shaykh de la Khalwatiyya, la réforme de la société passe par une purification de la voie spirituelle et une revivification du message coranique. Cette attitude n'est pas nouvelle, elle a toujours existé au sein du soufisme, mais elle acquiert davantage de signification à l'époque contemporaine où le soufisme est attaqué de tous les côtés.

Selon les représentations courantes, la fin du $\mathrm{xIX}^{\mathrm{e}}$ siècle et tout le $\mathrm{xx}^{\mathrm{e}}$ sont une période peu favorable au développement des confréries, du culte des saints et du soufisme dans son ensemble. Dès le XIXe siècle, les changements de la société moderne et l'influence d'un enseignement européen entraînent une déperdition de la tradition soufie. Les écrits doctrinaux sont plus rares et les manuels de soufisme ne font que reprendre les doctrines élaborées par les soufis de l'époque médiévale sur les techniques de dhikr ou sur les codes de politesse ( $(\hat{d} d a b)$ chez les soufis. Ce phénomène serait-il l'indice d'un déclin du soufisme et avec lui de toutes les pratiques liées à la sainteté comme le stipulent certains chercheurs ? ${ }^{21}$ Dès la fin du XIXe siècle, les confréries vont subir les attaques des réformistes religieux aussi bien que des intellectuels laïques : elles sont accusées par les uns de propager un islam déviant, par les autres d'abuser de la crédulité des paysans et de propager l'ignorance. Elles sont en somme rendues responsables du retard culturel et de la décadence des sociétés musulmanes.

Les biographes des shaykh ne sont pas seulement des auteurs, ils apparaissent aussi comme des acteurs totalement impliqués dans leur objet d'étude. Ainsi traitent-ils de la mystique dans un but polémique : il s'agit de la défendre des attaques dont elle fait l'objet. Leur profil spirituel, mais aussi la nécessité de se protéger contre un milieu hostile, explique leur discrétion sur les notions de sainteté (walâya), de connaissance de Dieu par inspiration et illumination ( $f a t h)$, de grâce divine (baraka) et de pouvoirs surnaturels, même si tout leur enseignement tourne autour de la sainteté. Dans les écrits sur les shaykh ou par les shaykh, le soufisme disparaît souvent complètement pour ne laisser la place qu'à un enseignement coranique. Les shaykh font apparaître le soufisme comme le respect du Coran et de la Sunna et l'application des vertus muhammadiennes (al-akhlâq al-muh'ammadiyya), lui enlevant ainsi toute sa dimension ésotérique et initiatique. Ils condamnent, autant que le font les réformistes, certaines pratiques liées au dhikr ou la vénération excessive portée au shaykh et la recherche de ses pouvoirs surnaturels. Ils vont parfois si loin dans leur volonté d'assimiler le soufisme au réformisme qu'ils ont tendance à imiter ce dernier, ce qui explique que des chercheurs aient vu en ces hommes, qui s'affirment aussi bien salafiyyîn que soufis, les représentants d'un soufisme rénové et " réformé $»^{22}$. Or, en alignant leur discours sur celui des réformistes, ces shaykh cherchent surtout à se protéger des attaques de leurs adversaires et à recruter dans toutes les classes de la société. 
27 Mais il existe une autre tradition sur la vie des shaykh, accessible par l'enquête de terrain. Cette tradition orale tourne aussi autour de la sainteté du shaykh, mais elle diverge de la tradition écrite sur un point fondamental : la baraka, c'est-à-dire la grâce divine.

Les signes de la sainteté

Alors que les biographes cherchent à multiplier les garanties d'orthodoxie de leur shaykh en mentionnant ses qualités scientifiques et spirituelles, les disciples insistent sur l'aspect merveilleux de la vie de ce dernier, ses miracles, ses longues retraites, son aspect physique et son comportement; ces éléments nous en disent plus long sur la réussite du shaykh que le discours salafi de façade adopté par ses biographes. En effet, les azharis forment une minorité au sein des disciples du shaykh ; la majorité appartient à des milieux populaires, ruraux, ou ruraux urbanisés. Ce sont ces derniers qui font la popularité et le charisme du shaykh, et pour eux, seule compte sa baraka. C'est une fois celle-ci reconnue que les fidèles affluent.

La baraka est pour les disciples la marque visible de la sainteté du shaykh, de son lien personnel à Dieu. Elle se manifeste à travers plusieurs éléments que tous les saints possèdent à différents degrés: une ascendance chérifienne, l'ascétisme, le savoir, l'austérité du comportement. Les informations recueillies oralement sur le shaykh Ahmad al-Tayyib al-Hassânî font la part belle à l'ascendance chérifienne, alors que pour les maitres de la Khalwatiyya, la filiation spirituelle est plus importante que la filiation héréditaire au Prophète. La famille al-Tayyib al-Hassânî se réclame de la descendance de Hassan, petit-fils du Prophète. L'un des ancêtres du shaykh aurait même été un compagnon du grand saint Ahmad al-Badawî. Cette généalogie prestigieuse, alliée à son comportement, joue un grand rôle dans la construction du charisme du shaykh alTayyib.

Toute une série d'anecdotes évoquent le comportement exemplaire du shaykh et de son fils, Muhammad, deux personnalités différentes mais possédant autant de charisme l'une que l'autre. Ahmad réunissait toutes les vertus attribuées aux saints: l'ascétisme et la piété - il faisait régulièrement dans une cellule des retraites accompagnées de jeûnes-, le détachement des biens de ce monde, la générosité. Il avait le don de clairvoyance et repérait ceux qui faisaient la prière ou le dhikr en état d'impureté majeure (janâba). Son entourage était sûr de ne jamais souffrir de la faim : «Pendant le mois de ramadan, raconte un fidèle, le shaykh était en voyage avec un groupe de disciples qui n'avait pas apporté de nourriture alors que le trajet était long et pénible. Quand approcha l'heure de la rupture du jeûne, les disciples, fatigués, firent remarquer au shaykh qu'ils n'avaient rien à manger. Ils entendirent alors l'appel à la prière et le shaykh leur demanda de regarder en direction de la Mecque; ils virent une table couverte de nombreux mets. »

Quant au fils, les disciples disent de lui qu'il était encore plus mutasawwuf que le père, ce qui signifie qu'il était plus strict en matière religieuse ; en effet, le terme mutasawwuf est interprété par les disciples comme étant "très religieux", alors que dans le soufisme, il est appliqué à quelqu'un qui aspire à devenir soufi. Il est vrai que le contraste entre le père et le fils est frappant, notamment dans leurs relations avec les disciples et avec les gens en général. La légende du shaykh Ahmad raconte que ce dernier était proche de ses fidèles, partageant le repas des plus pauvres et ne repoussant jamais quiconque se précipitait pour lui baiser la main afin de recevoir sa baraka. Le fils, au contraire, avait établi entre lui et ses disciples une telle distance qu'il 
prenait soin de couvrir sa main d'un tissu blanc lors du baisemain rituel (musâfaha). Il effectuait de longues retraites dans un réduit qui communiquait par une petite porte avec la mosquée et n'en sortait que pour aller prier. Le serviteur chargé de lui acheter sa nourriture ne devait serrer la main à personne sur son chemin, et seule sa fille Kalthûm était autorisée à lui préparer son unique repas de la journée, composé de légumes et de viande bouillie, sans sel ni épices. Il ne buvait ni thé ni café, ni aucune autre boisson en dehors d'une tisane d'anis tous les soirs.

Dans les codes de politesse de la Khalwatiyya ${ }^{23}$, il est écrit que les disciples ne doivent pas révéler les secrets du shaykh, ne pas l'espionner, ne pas chercher à savoir combien de temps il dort ni ce qu'il mange, au risque de rompre le pacte d'engagement. Pourtant les disciples du shaykh Muhammad connaissent en détail ce dont le shaykh se nourrissait, car cela fait partie de la construction de son charisme; en effet, pour les fidèles des saints, le corps de ces derniers est pur, lumineux et ne se décompose pas après leur mort. Selon ceux qui ont connu le shaykh Muhammad, son aspect extérieur fascinait: "II était entièrement habillé de blanc, des chaussures au voile qui lui couvrait la tête. À l'instar du Prophète, il aimait se parfumer et laissait pendre sur son cou la queue de son turban ». Il inspirait à tous un mélange de crainte et de respect (hayba) de sorte qu'ils baissaient les yeux en sa présence, par politesse mais aussi par crainte, la crainte d'avoir fait quelque chose de mal sans le savoir, car « le shaykh avait le pouvoir de lire dans le cœur des hommes ».

Conclusion

La tradition orale relative à la vie du shaykh Ahmad al-Tayyib et celle de son fils Muhammad montrent bien que des critères comme l'abnégation, l'abstinence, l'humilité, la générosité, la piété et tout ce qui est lié au comportement et à l'aspect physique sont inséparables du statut de guide spirituel : les signes de la sainteté doivent être perceptibles. Les bio-hagiographies consacrées aux shaykh de la Khalwatiyya reflètent rarement le comportement du shaykh avec ses disciples. La discrétion de l'écrit sur ce qui participe le plus de la construction du charisme du shaykh, c'est-à-dire la baraka et les miracles, est liée à l'époque, peu favorable à la transmission d'une tradition hagiographique riche et vivante, et au profil des biographes, influencés par leur formation à al-Azhar. Les biographies consacrées aux shaykh sont pauvres car elles sont apologétiques, axées sur la défense du soufisme; elles témoignent de la déperdition de la tradition soufie écrite, liée aux changements introduits par la modernité et à l'influence d'un islam fondamentaliste. On peut lire à travers elles les tensions et conflits existant chez ces soufis lettrés qui essaient d'adapter leur pratique à l'évolution de la pensée islamique contemporaine tout en préservant leur identité soufie.

\section{NOTES}

1. Al-Shârânî 'A. al-W., Al-Tabaqât al-kubrâ, Le Caire, 1954. Al-Tabaqât al-kubrâ, Le Caire, 1970. 
2. Les origines de la Khalwatiyya sont assez obscures; la fondation de la confrérie, dérivée de l'enseignement du Persan Ibrâhîm al-Zâhid, est attribuée à 'Umar alKhaIwalî (m. à Tabriz en 1397), appelé ainsi à cause de ses fréquenles retraites (khalwa). Cf. De Jong F., article " Khalwatiyya ", Encyclopédie de l'Islam (2), t. 2, p. 1023-1026. Bannerth E., « La Khalwatiyya en Égypte », MIDEO. 8,1964-1966, p. 63. Martin B. G., « A Short History of the Khalwatiyya Order ", in N. Keddie éd., Scholars, Saints and Sufis. Muslim Religious Institutions since 1500, UCP, 1972, p. 297.

3. Al-Jabartî 'A. a-fi.,'Ajâ'ib al-âthâr fî-l-tarâjim wa-l-akbâr, Le Caire, 1958-67, vol. 1, p. 286.

4. Sa'îdî: originaires du Sa'îd (Haute-Égypte).

5. Al-Hajjâjî M. 'A, Min a'lâm al-Sa'îd fi-l-qarn al-râbi' 'ashar al-hijri. Le Caire, 1969, p. 93-112.

6. Al-Hajjâjî M. 'A, Abd-l-Hajjâjj al-Uqsurî, Le Caire, 1968 ; Shakhsiyyât sûfiyya fî Sa'îd Misr fil-'asr al-islâmî, Le Caire, 1971 ; al-Uqsur fî-l-'asr ai'islâmî, Le Caire, 1986.

7. Manuscrit, Dâr al-kutub, târîkh 2487,3 volumes, 1922.

8. Manuscrit, Dâr al-kutub, mustala' 328, t. 2, 1896-1910.

9. Al-Tâhir 'A. al-R. et Mahmûd 'A. al-R., al-'Arif al-Dûmî, Le Caire, 1969,1990.

10. Al-'Arif al-Dûmî, op. cit., p. 35-39.

11. Sur ce personnage, voir G. Delanoue, Moralistes et politiques musulmans dans l'Égypte du XIX ${ }^{e}$ siècle (1798-1882), Ifao, Le Caire, 1982.

12. Geoffroy E., Le soufisme en Égypte et en Syrie sous les derniers Mamelouks et les premiers Ottomans. Orientations spirituelles et enjeux culturels, Ifead, Damas, 1995, p. 283.

13. Nafahât dûmiyya, p. 10, Le Caire, sd.

14. Sharqawi A., Shams al-tahqîq 'ala 'urwat ahl al-tawfîq, Le Caire, 1889. Cette épître porte sur la manière de prononcer les noms de Dieu (Asmâ' Allâh).

15. Al-Marâghî M., Safahât nasî'a, p. 18.

16. Al-Najânisî M., Al-Latâ'if al-fikriyya wa-l-nafahât al-ahmadiyya al-sharqâwiyya, manuscrit privé, p. 213.

17. Al-Hajjajî M. 'A., Min a'Iâm al-Sa'îd..., p. 52.

18. Ta'tîr, t.lll, p.35.

19. Al-Wafâ', I, p. 11. Le Riyâd al-sâlihîn du syrien al-Nawâwî (m. 1265\} est une collection de hadîfh sur la vie spirituelle, souvent réimprimée et que l'on trouve dans la plupart des librairies du Caire.

20. Nafahât, p.12.

21. Trimingham J. S., The Sufi Orders in Islam, Clarendon Press, Oxford, 1971. Gilsenan M., Saint and Sufi in Modem Egypt, Weindenfeld and Nicolson, Londres, 1973 ; « Some Factors of the Dedine of the Sufi Orders in Modem Egypt », Muslim World, 57,1967, p. 11-18.

22. Luizard P. J., « Le soufisme réformiste : l'exemple de trois confréries », Modernisation et nouvelles formes de mobilisation sociale. Dossiers du Cedej, 1992, p, 91-106.

23. Al-Dardîr A., Tuhfat al-ikhwân, Le Caire.

\section{INDEX}

Mots-clés : islam, réformisme, soufisme, biographie 
AUTEUR

RACHIDA CHIH

IFAO 